\title{
Elimination kinetics of diisocyanates after specific inhalative challenges in humans: mass spectrometry analysis, as a basis for biomonitoring strategies
}

\author{
Lygia T Budnik $^{1 *}$, Dennis Nowak², Rolf Merget ${ }^{3}$, Catherine Lemiere ${ }^{4}$ and Xaver Baur ${ }^{1}$
}

\begin{abstract}
Background: Isocyanates are some of the leading occupational causes of respiratory disorders, predominantly asthma. Adequate exposure monitoring may recognize risk factors and help to prevent the onset or aggravation of these aliments. Though, the biomonitoring appears to be most suitable for exposure assessment, the sampling time is critical, however. In order to settle the optimal time point for the sample collection in a practical biomonitoring approach, we aimed to measure the elimination of isocyanate urine metabolites.

Methods: A simple biomonitoring method enabling detection of all major diamine metabolites, from mono-, polyand diisocyanates in one analytical step, has been established. Urine samples from 121 patients undergoing inhalative challenge tests with diisocyanates for diagnostic reasons were separated by gas chromatography and analyzed with mass spectrometry (GC-MS) at various time points (0-24 h) after the onset of exposure.

Results: After controlled exposures to different concentrations of diisocyanates (496 \pm 102 ppb-min or $1560 \pm 420$ ppb-min) the elimination kinetics (of respective isocyanate diamine metabolites) revealed differences between aliphatic and aromatic isocyanates (the latter exhibiting a slower elimination) and a dose-response relationship. No significant differences were observed, however, when the elimination time patterns for individual isocyanates were compared, in respect of either low or high exposure or in relation to the presence or absence of prior immunological sensitization.

Conclusions: The detection of isocyanate metabolites in hydrolyzed urine with the help of gas chromatography combined with mass spectrometric detection system appears to be the most suitable, reliable and sensitive method to monitor possible isocyanate uptake by an individual. Additionally, the information on elimination kinetic patterns must be factored into estimates of isocyanate uptake before it is possible for biomonitoring to provide realistic assessments of isocyanate exposure. The pathophysiological elimination of 1,6-hexamethylene diamine, 2,4diamine toluene, 2,6-diamine toluene, 1,5-naphthalene diamine, 4,4'-diphenylmethane diamine and isophorone diamines (as respective metabolites of: 1,6-hexamethylene diisocyanate, 2,4-toluene diisocyanate and 2,6 toluene diisocyanate, 1,5-naphthalene diisocyanate, 4,4'-diphenylmethane diisocyanate and isophorone diisocyanates) differs between individual isocyanates' diamines.
\end{abstract}

Keywords: isocyanates biomonitoring, biological monitoring, exposure assessment, occupational asthma, hypersensitivity pneumonitis, specific inhalation challenge

\footnotetext{
* Correspondence: L.Budnik@uke.uni-hamburg.de

'Institute for Occupational Medicine and Maritime Medicine (ZfAM)

University Medical Center, Hamburg-Eppendorf, Hamburg, Germany

Full list of author information is available at the end of the article
} 


\section{Background}

The lungs represent the first line of defense against challenges by a variety of environmental dusts, gases, fumes and vapors. Agents like diisocyanates have the capacity to irritate, sensitize and induce toxic effects in the respiratory tract $[1,2]$, depending on the concentration and duration of exposure as well as their physicochemical properties. Exposure to isocyanates occurs either during manufacture (i.e. of foams, elastomers) or during application of spray paints, varnishes, surface coatings, hardeners or binders. Isocyanates, which are characterized by the highly reactive $\mathrm{N}=\mathrm{C}=\mathrm{O}$ groups, are one of the most frequent causes of occupational asthma and can also elicit hypersensitivity pneumonitis and accelerated lung function loss [3-7].

Clinical diagnosis and the differential identification of isocyanates as the cause of work-related disorders are often difficult because of multiple exposures (i.e. to HDI and to MDI/TDI during spray painting) $[1,3,7]$. Exposure monitoring may recognize risk factors for disease development and help to prevent the onset or aggravation of disease. Efficient methods are needed to improve both primary preventive measures and the surveillance of exposed workers. The increasing use of isocyanates in industrial applications worldwide has increased the likelihood of exposure events in both production plants and during transport. A reliable measurement system of incidental exposure would also benefit bystanders and members of the general public, as well.

Contamination of the air provides the major route for isocyanate uptake, but the pattern of exposure cannot be fully characterized by simply monitoring air contamination. Heavy work increases physical demands and ventilation, exacerbating the degree of incorporation. Absorption through the skin, ingestion and individual differences in metabolism should also be considered [8-11]. Furthermore, the measurement of isocyanate levels in air is complicated [12] by the various physical states of isocyanates, as they may occur as gases or aerosols (in particles or droplets of various sizes). Thus, biomonitoring appears to be most suitable tool for assessing the various exposure scenarios. Feasible analytical methods for the detection of individual isocyanate metabolites in urine have been described [13-17]. Important data for the design of biomonitoring strategies is largely absent, however, with the exact time point of sampling being especially critical. In order to develop guidelines for adequate exposure control in future, biomonitoring based on standardized methods and ascertained kinetic data is needed.

Stable and reproducible amounts of isocyanates can only be obtained under experimental conditions and, in order to understand the excretion patterns of isocyanate metabolites, the use of a controlled isocyanate atmosphere is essential. The aim of this study was to use the data from such controlled studies to estimate the elimination kinetics of the most widely used isocyanates.

\section{Methods \\ Study subjects}

The 121 patients involved in this study were referred to the four outpatient clinics by general physicians, the workers compensation boards or statutory accidental insurance institutions for an extensive occupational asthma diagnosis [18]. The study was approved by the respective Institutional Ethics Committees (to XB in Hamburg; to DN in Munich; to RM in Bochum and to $\mathrm{CL}$ in Montreal). All participants gave written informed consent. All subjects had previous occupational exposure to isocyanates (0.3-10 years): 110 males and 11 females with a median age of 45 (20 to 60) years. All subjects reported prior or current work-related respiratory symptoms (shortness of breath and wheezing). 50 (42\%) were non-smokers, 58 (48\%) were ex-smokers and $12(10 \%)$ were current smokers. 44 (37\%) were defined as atopic after skin prick testing with common environmental allergens. The prevailing respiratory symptoms and medical and occupational histories were assessed by physician interviews. Serum creatinine concentrations were within the normal range and none had evidence of renal or hepatic disorders. The gold standard for verifying isocyanate-induced asthma is a specific inhalation challenge (SIC), which can only be performed in a few highly specialized centers in the world [7]. All 121 subjects underwent SIC by several isocyanates (HDI, MDI, TDI, NDI or IPD) in one of the four participating centers. A period of at least three days without known occupational exposure was kept in each case prior to the investigation. 30 subjects (25\%) of the study group showed positive SIC results (defined as an asthmatic reaction with a fall of $\mathrm{FEV}_{1} \geq 20 \%$ ), 42 subjects (35\%) showed bronchial hyperresponsiveness (NSBHR) as evaluated by methacholine challenge testing, according to the centers definition. 17 subjects (14\%) had specific IgE antibodies to the particular isocyanate. During followup, $25 \%$ of the patients were removed from their workplace exposure and $75 \%$ underwent or are currently undergoing exposure control.

\section{Isocyanate exposure}

All patients underwent SIC using the isocyanate used at their workplaces [19]. They were exposed to the airborne isocyanate with moderate working load (in Hamburg and Munich) in c. $10 \mathrm{~m}^{3}$ exposure chambers where a fan system ventilated the air mixture at a rate of $6.5 \mathrm{~m}^{3} / \mathrm{min}$ (Hamburg, Munich, Bochum) or with a closed-circuit apparatus (Montreal) [1]. The generation of diisocyanate (HDI, MDI, TDI, NDI or IPDI) standard 
atmospheres was performed with gas-liquid permeation. In detail, permeation tubes were placed in a generation flask containing about $20 \mathrm{~mL}$ isocyanates ( $\geq 99 \%)$ containing either IPDI (in case of IPDI a mixture of cisand trans-isomers), 4,4'-MDI, 2,4-/2,6-TDI, 1,6-HDI or 1,5-NDI. Briefly, the solution was heated to either $60^{\circ} \mathrm{C}$ (HDI, IPDI), $80^{\circ} \mathrm{C}$ (TDI) or to $145^{\circ} \mathrm{C}$ (MDI) on a heating block generating an isocyanate-enriched atmosphere under a constant pressure of $1.2 \mathrm{~L} / \mathrm{min}$. Isocyanate concentrations in the exposure chamber were monitored with a gas monitoring device system instrument (MDA scientific 7100, Honeywell, Zellweger, Hamburg, Germany). Calibration was performed as recommended by the manufacturer. Additionally, a part of the isocyanate air samples was measured with the HPLC filter extraction method. The relative humidity was $35-50 \%$ and the temperature $20-25^{\circ} \mathrm{C}$ as measured by thermohydrometer. Air samples were measured in 2 min intervals by the MDA scientific monitor inside the exposure chambers. Subjects were exposed to the respective isocyanate (i.e. HDI, TDI, MDI, NDI or IPDI) at concentrations between 0.5 and $30 \mathrm{ppb}$ for 0 to 120 minutes. The averaged cumulative median concentration was $5.5 \pm$ $5.1 \mathrm{ppb}$ (see additional file 1,2,3 and 4 for details on the method). For data analysis, the study subjects were divided into two exposure groups: low $3.1 \pm 1.2 \mathrm{ppb} /$ max. $120 \mathrm{~min}$, or high $13 \pm 7 \mathrm{ppb} / \max .120 \mathrm{~min}$ (shown as gemometric mean \pm SD). The inhalative uptakes were estimated as pulmonary ventilation exposure level $x$ duration of exposure. The calculated isocyanate load was $496 \pm 103 \mathrm{ppb}$-min (for the low exposure group) and $1569 \pm 420 \mathrm{ppb}$-min (for the high exposure group). $\mathrm{FEV}_{1}$ was measured before exposure, in $10 \mathrm{~min}$ intervals within the first hour, then every hour until $6 \mathrm{~h}$ as well as $24 \mathrm{~h}$ after exposure. The urine samples from all patients were collected, according to the settled sampling protocol (see also additional files 1, 2, 3 and 4), at various time points starting from the beginning of the challenge ( 0 point) up to $24 \mathrm{~h}$, for each person at the given time points. To deliver spot urine samples the patients were given sterile $100 \mathrm{~mL}$ polyethylene plastic containers and were asked to wash the hands before voiding to avoid dust failing into the sampling container (e.g. from cloth and skin), The samples were placed in a cool box and send to the analyzing laboratory; aliquots were prepared after vigorous shaking of the sample and were immediately frozen $\left(-20^{\circ} \mathrm{C}\right)$.

\section{Analysis of isocyanate metabolites}

The determination of urine metabolites was based on our previously published methods for the single HDA measurements [17] and a single MDA measurementmethod published by other group [20] taking advantage of the known biotransformation of isocyanates to respective biological amines and the detection of the parent aromatic amines after acid hydrolysis of urine samples $[16,20,21]$. The released aromatic amines were separated by gas chromatography and detected by mass spectrometry (GC-MS). The method was modified to perform simultaneous analysis of the metabolites of the following occupational isocyanates in urine: 1,6-HDI, 4,4'-MDI, 2,4-TDI, 2,6-TDI, 1,5-NDI as well as the metabolites of cis- and trans IPDI isomers (Figure 1), thus allowing the monitoring of isocyanate co-exposure mixtures.

It has been recognized earlier that acid hydrolysis yields higher amine values (i.e. 6.5 times higher MDA values were detected). Not only free isocyanate amines,

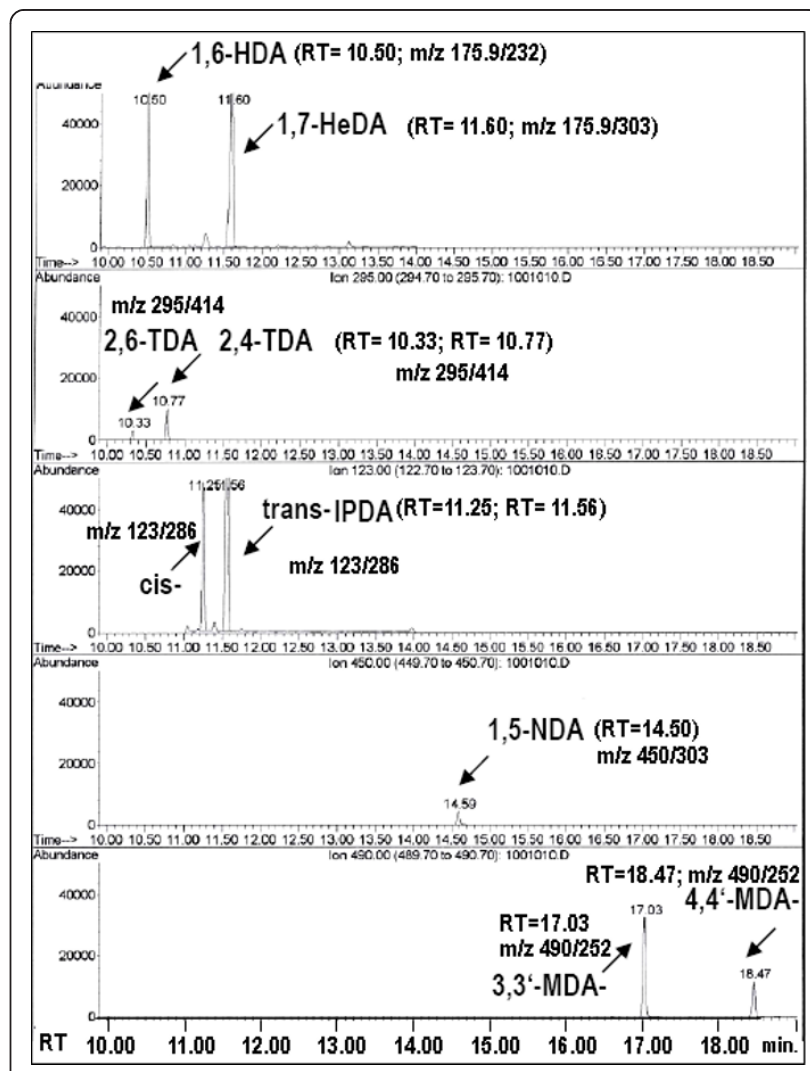

Figure 1 The GC-MS analysis of isocyanate diaminemetabolites. Urine samples were subjected to strong acid hydrolysis, separated with gas chromatography (GC) and the individual isocyanate diamines were detected with mass spectrometry (MS), as described in methods. Data show the individual retention time (RT) points (after the GC column separation) and their respective mass/charge (m/z) data (MS detector) with the individual target und qualifier ions allowing to recognize the following metabolites: 1,6 HDA (used to detect 1,6HDI exposure), 2,4-TDA, 2,6-TDA (to detect 2,4 and 2,6-TDI exposure), cis- and trans- IPDA (to detect exposure to isophorone diisocyanates), 1,5-NDA, (to detect exposure to 1,5 NDI), 4,4'-MDA (to detect exposure to 4,4'-MDI). Additionally, 1,7-HeDA and 3,3'MDA were used as internal control standards. 
but also additionally bound isocyanates and the conjugates thereof can be detected by this hydrolysis-based method. The acid hydrolysis splits many possible conjugates which might be present in urine like mercapturic acid, glucoronic acid as well as acetyl-/diacetyl isocyanate diamines to corresponding MDA, HDA, TDA, NDA and IPDA. For the current analysis, all patient samples, standards and controls were subjected to strong acid hydrolysis to yield the respective amines: $6 \mathrm{M} \mathrm{HCl}$ was added to $2 \mathrm{~mL}$ urine, which was hydrolyzed at $100^{\circ} \mathrm{C}$ for 12 hours, the samples were chilled and made basic with saturated $\mathrm{NaOH}$. The samples were extracted with toluene; after the phase separation two $\mathrm{mL}$ dried organic phase by $\mathrm{Na}_{2} \mathrm{SO}_{4}$ were used in derivatization by adding $25 \mu \mathrm{L}$ pentafluoropropionic anhydride. The vials were closed tightly and shaken for $1 \mathrm{~min}$. The derivatization was stopped by adding $3 \mathrm{~mL}$ $1 \mathrm{M}$ phosphate buffer $(\mathrm{pH}$ 7.5) and was shaken for $10 \mathrm{~min}$. After centrifugation, the organic phase was supplemented with $100 \mu \mathrm{L}$ n-decane as keeper and then evaporated with nitrogen to a residual volume of about $100 \mu \mathrm{L}$. Two $\mu \mathrm{L}$ of this solution containing the amide derivative were analyzed by GC-MS in a selected ionmonitoring mode on a Agilent mass spectrometry detector MSD HP 5973 connected to a gas chromatograph HP 6890, equipped with an auto-sampler. The separation was performed on a capillary column HP-5MS (30 $\mathrm{m} \times 0.25 \mathrm{~mm}$ ) with a film thickness of $0.5 \mu \mathrm{m}$. The column was held at $100^{\circ} \mathrm{C}$ for $2 \mathrm{~min}$, ramped at $10^{\circ} \mathrm{C} / \mathrm{min}$ to $280^{\circ} \mathrm{C}$. Injections were performed in the split less mode under helium at a flow rate of $2.0 \mathrm{~mL} / \mathrm{min}$. Under these conditions, the retention times (RT) for cis-IPDA and trans-IPDA were $11.25 \mathrm{~min}$ and $11.56 \mathrm{~min}$, respectively; the specific ions $\mathrm{m} / \mathrm{z}$ (mass/charge) was $123(\mathrm{~m} / \mathrm{z}$ for target ion) and 286 ( $\mathrm{m} / \mathrm{z}$ for qualifier), respectively; for 4,4' MDA the RT was $18.47 \mathrm{~min}$ and $\mathrm{m} / \mathrm{z}$ was 490 / 252; for 2,4- und 2,6-TDA: $10.33 \mathrm{~min}$ and $10.77 \mathrm{~min}$ (with $\mathrm{m} / \mathrm{z}$ 295/414); for 1,6-HDA, $10.50 \mathrm{~min}$ (with $\mathrm{m} / \mathrm{z}$ $175.9 / 232$ ) and for $1,5-\mathrm{NDA} 14.50 \mathrm{~min}$ (with $\mathrm{m} / \mathrm{z} 450$ / 303); The RT for 1,7-HeDA was $11.60 \mathrm{~min}(\mathrm{~m} / \mathrm{z} 175.9$ /

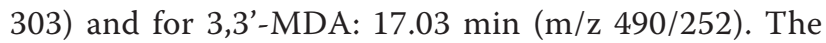
method distinguishes the following isocyanate amines (with the respective instrumental detection limits as shown): 2,4-TDA $(0.1 \mu \mathrm{g} / \mathrm{L}), 2,6$-TDA $(0,15 \mu \mathrm{g} / \mathrm{L})$; 4,4'MDA $(0.1 \mu \mathrm{g} / \mathrm{L}) ; 1,6$ HDA $(0.5 \mu \mathrm{g} / \mathrm{L}) ; 1,5-\mathrm{NDA}$ $(0.5 \mu \mathrm{g} / \mathrm{L})$ and both isoforms of IPDA, $(0.5 \mu \mathrm{g} / \mathrm{L})$. The 1,7-HeDA and 3,3'-MDA were used as internal standards (to determine the recovery). For interpretation of the data, the peak areas of individual analyzed amines were divided by the peak areas of individual standards. Using this quotient the amine concentrations were estimated with standard curves for each individual isocyanate-amines' run in parallel. Analytical standards for each individual diamine were used to prepare standard calibration curves (7 points). The quantifications were achieved by comparison with these calibration curves (prepared for 1,6 HDA, 2,4-TDA, 2,6-TDA, 4,4'-MDA, 1,5-NDA, both IPDA isomers) in the range of 5 to 100 $\mu \mathrm{g} / \mathrm{L}$ for each metabolite; additionally; external positive and negative controls were measured within the same analytical step (see Table S2). The analytical limits of detection (LODs) were calculated according to the formula: $y B+3 * \mathrm{sB}$ and were $0.2 \mu \mathrm{g} / \mathrm{L}$ for $2,4-\mathrm{TDA}, 0.2$ $\mu \mathrm{g} / \mathrm{L}$ for 2,6-TDA, $0.3 \mu \mathrm{g} / \mathrm{L}$ for 4,4'-MDA, $1.0 \mu \mathrm{g} / \mathrm{L}$ for $1,5-\mathrm{NDA}, 1.0 \mu \mathrm{g} / \mathrm{L} 1,6 \mathrm{HDA}$ and $1.0 \mu \mathrm{g} / \mathrm{L}$ for both IPDA isoforms. The levels of the measured isocyanate diamines varied from $<0.1 \mu \mathrm{g} / \mathrm{L}$ to $250 \mu \mathrm{g} / \mathrm{L}$ for the time points $0-24 \mathrm{~h}$ after the onset of the inhalation challenge. We assessed the method for reproducibility, linearity and sensitivity. Control set points prepared from calibrated standards (see Table S1 for the failure ranges) and control urine samples from non-exposed (5-20 volunteers) and control urine samples from exposed subjects were used as additional internal laboratory controls. The urine samples from non-exposed subjects were below the LOD and the positive controls did not show cross-reactivity (see Table S2 for representative data). All urine values were creatinine-corrected for each sample (the isocyanate concentrations were expressed in $\mu \mathrm{g}$ per $\mathrm{g}$ of creatinine). Urinary creatinine was determined in grams per liter $(\mathrm{g} / \mathrm{L})$ using HPLC. The method involves the pretreatment of the samples with trichloracetic acid and centrifugation followed by the isocratic separation of compounds on a $\mu$-Bondapak C18 column using a mobile phase consisting of 1.25 $\mathrm{mmol} / \mathrm{L}$ tetrabutylammonium phosphate (see also additional files 1, 2, 3 and 4 for further details of the methods, validation and controls and materials).

\section{Data analysis}

The excretion of the isocyanate diamines was expressed as median values \pm SD (standard deviation) of the respective amine, per $g$ creatinine over the individual time periods. Each sample analysis was performed twice. The data has been divided into low $(\mathrm{L})$ and high $(\mathrm{H})$ exposure groups with $496 \pm 103 \mathrm{ppb}$-min and $1569 \pm$ $420 \mathrm{ppb}$-min (mean $\pm \mathrm{SD}$ ), respectively. The averaged cumulative mean exposure was calculated for all isocyanates and was used to estimate the general excretion times for each individual isocyanate. To correlate the differences in the excretion times for the respective isocyanate amines between the various groups, the data were sampled using the Pearson approximation method to perform the correlation analysis (the correlation coefficient was calculated to show possible differences between the exposure groups at various time periods after exposure). Geometric means were calculated from the data comprising all groups to estimate the average 
elimination time patterns for the individual isocyanate diamines. The data analyses were performed with GraphPAD Prism-Software (GraphPad Software Inc., San Diego, CA).

\section{Results}

The median values calculated for each individual time point and the respective isocyanates are shown in the Figures $2 \mathrm{~A}-\mathrm{F}$. The data was used to estimate the excretion peaks and to calculate the elimination half-lives for low and high exposure groups (). Figure $2 \mathrm{~A}$ shows the mean values for 55 workers exposed to 1,6-HDI; the 1,6-HDA excretion levels demonstrate a major peak at $2 \mathrm{~h}$ and a second smaller one $15 \mathrm{~h}$ after the onset of the inhalative challenges, giving a calculated excretion half time of $2.5 \mathrm{~h}$. Figure $2 \mathrm{~B} / \mathrm{C}$ shows the elimination times for the metabolites of the two aromatic isocyanates (2,4-/2,6-TDI). The 2,4-TDA peaked at $4.1 \mathrm{~h}$ and 2,6TDA at $4.8 \mathrm{~h}$, the estimated half time for TDA was $6 \mathrm{~h}$ $(\mathrm{n}=18)$. It is known that the respective industrial products represent a mixture of 2,4- and 2,6-TDA which is used at the majority of workplaces. The excretion time for 4,4'-MDA $(\mathrm{n}=36)$ is given in Figure 2D, and shows a peak at $14 \mathrm{~h}$ after the exposure. Figure $2 \mathrm{E}$ indicates that the urinary excretion of IPDA peaked at $5.6 \mathrm{~h}$ after exposure. The complete elimination of IPDA in the urine was still not reached after $24 \mathrm{~h}$ (see below). It has to be noted that the elimination patterns for MDA and
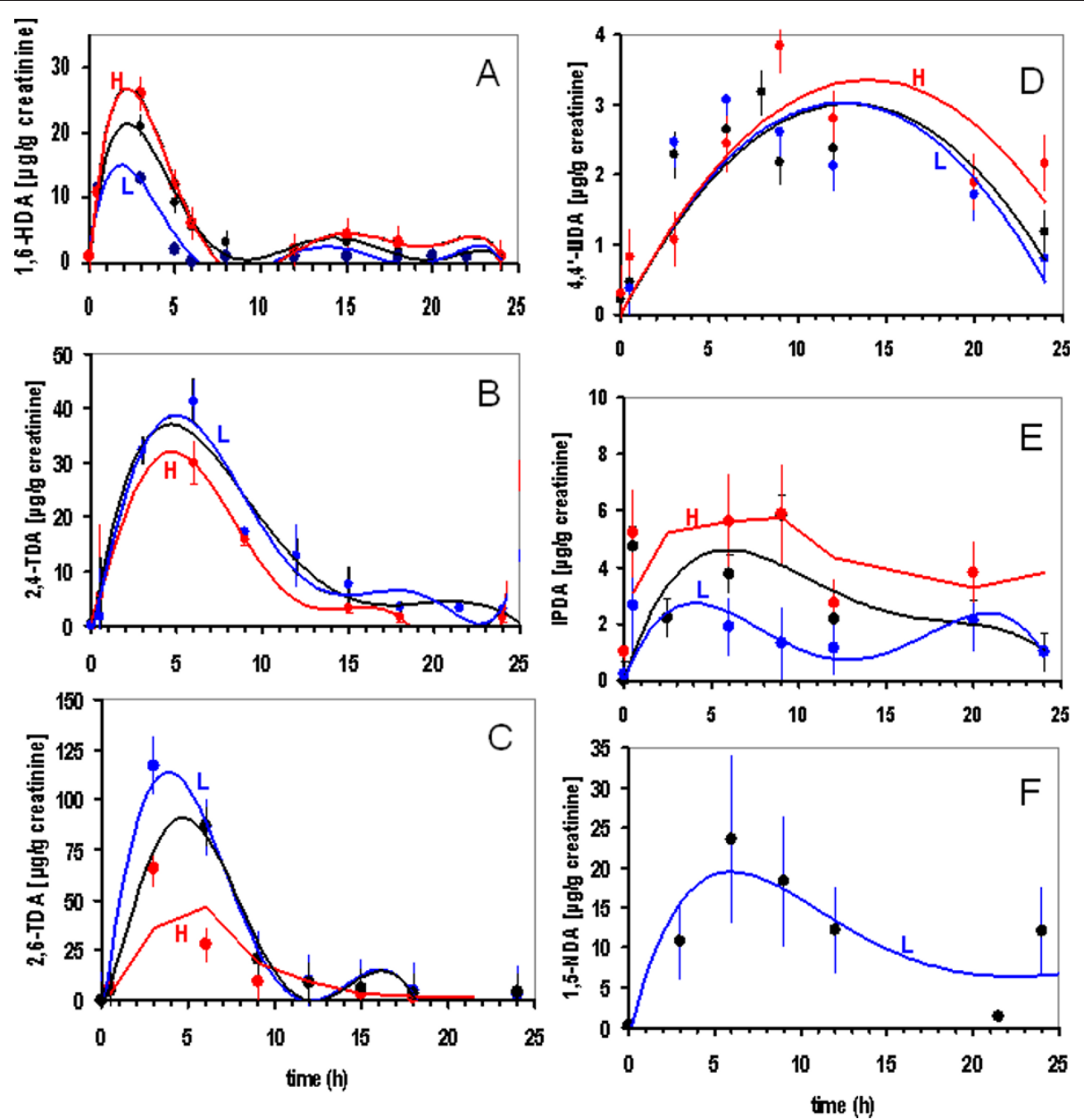

Figure 2 Elimination kinetics for isocyanate-diamines: 1,6-HDA (A), 2,4-TDA (B), 2,6-TDA (C), 4,4'-MDA (D), sum of the cis- and transIPDA isomers (E) and 1,5-NDA (F) in urine of patients after inhalation challenge with either 1,6 - HDI $(n=55), 2,4-$ TDI $(n=18), 2,6-$ TDI $(n=18), 4,4^{\prime}-\mathrm{MDI}(\mathrm{n}=36)$, IPDI $(n=9)$ or $1,5-\mathrm{NDI}(\mathrm{n}=3)$, respectively. Spot urine samples were voided by the patients at various time points (the collection times are shown on the $x$ axis) after the controlled exposure $(0-24 \mathrm{~h})$. The data points on the $Y$ axis represent median diamine values (expressed as $\mu \mathrm{g} / \mathrm{g}$ creatinine) with standard deviations for the patient samples detected with mass spectrometry (analysed against analytical standards for each individual diamine). The trend curves are shown for the low, $496 \pm 103$ ppb-min (blue, L) as well as high, $1560 \pm 420 \mathrm{ppb}-\mathrm{min}(\mathrm{red}, \mathrm{H}$ ) exposure groups (see additional files 1, 2, 3 and 4 for details on patient exposure and sampling). The geometric mean was calculated for the cumulative values from all patients to estimate the excretion time points for each individual isocyanate and to calculate the overall trend patterns (black lines). 
IPDA did not show as clear excrection peaks as for TDA or HDA.The elimination kinetics for $1,5-\mathrm{NDA}$ is shown in Figure 2F. Given the reservations arising from the small size of the group with NDI exposure $(n=3)$, the excretion of NDA peaked at $6.0 \mathrm{~h}$ with an additional late peak at $>48 \mathrm{~h}$.

Elevated peaks could be seen for the higher exposure groups for $1,6-\mathrm{HDA}$ (with $\mathrm{r}=0.86$, when the elimination kinetics trends were compared between the low and high exposure groups), 4,4'-MDA and IPDA, but not for 2,4-TDA and 2,6-TDA. For all isocyanate diamines there was a small non-significant shift of excretion for all high exposure groups (as compared to the low exposure groups). This might indicate slightly slower elimination kinetics. A slight shift to longer time periods is evident when comparing the excretion of 4,4'MDA and IPDA metabolites between the low and high exposure groups $(r=0.7, r=0.7$ elimation trendpatterns for 4,4'-MDA and IPDA, respectively).

Across the individual patient groups, the isocyanate metabolites show similar excretion kinetics patterns. Neither the SIC outcome, the NSBHR nor immunological parameters appear to influence the pathophysiological elimation of individual metabolites. For patients showing either a positive or negative SIC reaction (when the elimimation kinetics were compared between patients with positive or negative SIC reaction) or for patients with or without specific IgE antibodies and confirmed asthma diagnosis, there were no discernable changes in the excretion pattern (no statistically significant differences in $\mathrm{r}$ values between the individual groups). See also Figures S1a, S1b in additional file 4 for examples with individual patients.

\section{Discussion}

The sensitive and specific assessment of exposure to airborne agents is a precondition for effective prevention measures and health risk assessment. Air monitoring can be a problem because isocyanate aerosols and simultanous exposures to more than one isocyanate, frequently present in the workplace, are not adequately measured by many routine devices [22]. It has been shown that isocyanate exposure can occur despite respiratory protective equipment, and skin absorption or ingestion also having to be considered [8]. Previous studies have shown that the detection of isocyanate-derived (di-) amines in hydrolyzed urine is the most suitable, acceptable and sensitive method for monitoring potential individual isocyanate exposures [23-26]. Earlier studies provided some evidence that the urine excretion time may differ for individual isocyanates [24,26,27]. We corroborated the differences in excretion kinetics for different isocyanates and have established the elimination patterns for all major diisocyanates at different exposure concentrations. When looking closer at different isocyanates, it became obvious that the aliphatic isocyanate 1,6-HDI has a shorter excretion time than aromatic isocyanates (4,4'-MDI, 2,4-/2,6-TDI). Notably, aromatic MDA, NDA and cycloaliphatic IPDA were not completely eliminated after $24 \mathrm{~h}$. After pulmonary absorption of 2,4- and 2,6-TDI, the majority had been excreted in urine $6 \mathrm{~h}$ after the end of exposure [23,28].

According to other studies, additional slowly generated TDA fragments were released into urine over days $[28,29]$. Other groups could not monitor any longterm release of TDA into the urine [25]. We observed the major excretion peak at $4.1 \mathrm{~h}$ and $4.8 \mathrm{~h}$ (for 2,6- and 2,4-TDA); the majority of the TDA appeared to be eliminated after $24 \mathrm{~h}$. At high exposure levels, the TDA was eliminated more slowly with a half time of $6 \mathrm{~h}$.

It has to be noted however that the patients were exposed to a mixture of 2,4-/2,6-TDI, which might influence the elimination of a single diamine, a greater exposure group is necessary to prove this hypothesis. Unfortunately, in many studies only pre- and postworking shift data are provided. This may lead to misinterpretation of the actual exposure since only $15-20 \%$ of the residual 2,4- and 2,6-TDA is found after $8 \mathrm{~h}$.

In many industrial workplaces, exposure to several isocyanates may take place simultaneously and no information is available about how the different isocyanates are metabolized when the atmosphere contains a mixture of several isocyanates, such as e.g. during thermal degradation of polyurethanes. Other authors have identified MDA in pooled urine samples after exposure to MDI from thermal breakdown $[15,20,30]$. A high variability in TDA and MDA concentrations was described in urine during and between workdays [31-33], but information on the elimination half-times of MDA or NDA was not available as yet. We observed clear excretion peaks between 12-14 $\mathrm{h}$ after the end of exposure, revealing urinary elimination of MDA that is significantly slower than for other isocyanate amines. It was also evident that the excretion was not complete after $24 \mathrm{~h}$. We observed similarly slow elimination rates for another aromatic diisocyanate, 1,5-NDI, in another investigation of workplace exposure, with elimination times over 2-5 days in 6 workers (data not shown). We have estimated the excretion half-life for IPDA to be 4-5.5 h (for low and high exposure groups, respectively). In an earlier IPDI exposure study, the urinary elimination halftimes of IPDA excretion seemed to be slightly faster, reaching the half-time of excretion values between 1.7-4.3 h for subjects not previously exposed [34].

Our findings indicate that there is a clear difference in the excretion kinetics for individual isocyanates. Thus the measurements obtained after a working shift may falsely estimate the degree of exposure, especially for the 
aliphatic HDA with extremely short excretion times or aromatic isocyanates (i.e. MDA, NDA) with their longer excretion times. Interestingly, increasing the isocyanate load during the exposure challenge did not change the overall kinetic patterns, rather inducing a more prolonged horizontal shift (i.e. MDA, IPDA). There were only small differences in the excretion kinetics for the low and high exposure groups of investigated subjects when the individual peak hights were compared. It cannot be excluded that the isocyanate may metabolize differently if air concentrations are higher than those in this study.

Neither prior isocyanate exposure, bronchial hyperresponsiveness nor immunological sensitization to isocyantes were associated with changes in the pattern of the elimination kinetics. It had been proposed that chronically exposed workers might metabolize isocyanates differently than volunteers without prior exposure [33]. We cannot exclude this, but we found similar elimination kinetics for individual diisocyanates despite the different occupational pre-exposure histories of the subjects, their clinical status and different demographic and geographic origins.

It is likely that the same metabolizing enzyme or various (produced) adducts influence the elimination kinetics. The molecular pathomechanism of the isocyanate transport to an affected organ, the development of the disease and its elimination from the body are largely unknown for humans. It is assumed that the isocyanates are hydrolysed to their respective amines and further oxidized by the cyclooxygenase, CYP, to N-hydroxyarylamine and to nitroso compounds with glutathione as an important vehicle $[14,15,35]$, with enzyme polymorphisms presumably having an effect. The short lifetime of isocyanate amines means that urinary sampling is often too late, limiting their applicability as a useful biomarker of recent exposure. To monitor longterm exposure, other biomarkers could be considered, with the measurement of DNA- and/ or protein adducts offering promise. Novel industrial isocyanates may need modifications of the currently proposed methods for monitoring exposures, especially if they differ substantially from the usual chemical entities.

A major advantage of biomonitoring urinary metabolites is the provision of a measurement that reflects the total dose of isocyanates absorbed by the body by all routes. The simultaneous screening of the urine metabolites of aromatic, aliphatic and cycloaliphatic isocyanates enhances the probability of detecting previously unappreciated exposure. Using this method, we performed the biomonitoring of a group of 55 car industry workers and detected a high exposure to a totally unexpected isocyanate source, which proved to be a novel paint formulation recently introduced into the working process [36].

\section{Conclusions}

The detection of isocyanate metabolites in hydrolyzed urine with the help of GC-MS appears to be the most suitable, reliable and sensitive method to monitor possible isocyanate uptake by an individual. The simplified sample collection of spot urine, increases both the acceptance and penetrance of monitoring for both patients and physicians. Simultaneous screening within the same analytical step enables the effective monitoring of mixtures of monoisocyanates, diisocyanates and oligoisocyanates, which are the prevailing substances in various industrial settings. Since excretion kinetics patterns vary for different isocyanates, these kinetics must be considered in planning biological monitoring in which urinary elimination is used as an estimate of uptake. Two different sampling time points might be appriopriate for most work settings.

\section{Additional material}

Additional file 1: Materials.

Additional file 2: Supplementary data to the methods.

Additional file 3: Validation data to the GC-MS-method.

Additional file 4: Examples of individual patient data.

\section{Abbreviations}

1,6-HDI: (1,6-hexamethylene diisocyanate); 2,4-TDI, 2,6-TDI: (2,4- and 2,6 toluene diisocyante); 1,5-NDI: (1,5-naphthalene diisocyanate); 4,4'- MDI: (4,4'diphenylmethane diisocyanate; IPDI: (isophorone diisocyanate); IPDA: (Isophorone diamine); 1,6 HDA: (1,6-hexamethylene diamine); 1,7 HeDA: (1,7diaminoheptane); 2,4-TDA: (2,4-diamintoluene); 2,6-TDA: (2,6-diamintoluene); 1,5-NDA: (1,5-naphthalene diamine); 4,4'-MDA: (4,4'-diphenylmethane diamine); 3,3'-MDA: (3,3'-methylene dianiline); SIC: (specific inhalation challenge); NSBHR: (nonspecific bronchial hyper responsiveness); SPT: (prick test)

\section{Acknowledgements}

The study is a part of the WHO GPA (Global Plan of Action) project for occupational health (LTB). The study was partially supported by the State Ministry of Health, Family and Consumer Protection, Hamburg (XB, LTB) and by the German Research Council, DFG (XB).

The authors thank Mrs K-H Tieu, Institute for Occupational Medicine and Maritime Medicine, Hamburg for her engagement in performing the GC-MS analysis and contribution to the methods development and Dr. Kevan Willey from the University Bioinformatics Centre for his critical evaluation of the manuscript. We would like to acknowledge that this work could not have been done without the contribution of many colleagues and coworkers who helped with the isocyanate challenge tests and sample collection in the participating centers.

The Corresponding Author does grant an exclusive licence to the Journal of Occupational Medicine and Toxicology (or non exclusive for government employees) on behalf of all authors.

\section{Author details}

${ }^{1}$ Institute for Occupational Medicine and Maritime Medicine (ZfAM),

University Medical Center, Hamburg-Eppendorf, Hamburg, Germany.

${ }^{2}$ Institute and Outpatient Clinic for Occupational, Social and Environmental 
Medicine, Ludwig-Maximillian-University Munich, Germany. ${ }^{3}$ Institute for Prevention and Occupational Medicine of the German Social Accident Insurance, Institute of the Ruhr-University (IPA), Bochum, Germany. ${ }^{4}$ University de Montréal, Departement of Medicine, Centre de recherche de I'Hôpital du Sacré-Coeur de Montréal, Montréal, Canada.

\section{Authors' contributions}

XB planed the study, XB, RM, DN, CL have supervised the specific inhalative challenges, the examination of the patients and diagnosis; LTB was responsible for all laboratory tests; LTB/XB drafted the manuscript, LTB wrote the mansuscript. All the authors have read and approved the final version of the manuscript.

\section{Competing interests}

None of the authors has a financial relationship with a commercial entity that has an interest in the subject of this manuscript.

Received: 12 October 2010 Accepted: 29 March 2011

Published: 29 March 2011

\section{References}

1. Malo JL, Ghezzo H, Elie R: Occupational asthma caused by isocyanates: patterns of asthmatic reactions to increasing day-to-day doses. Am J Respir Crit Care Med 1999, 159(6):1879-1883.

2. Pronk A, Preller L, Raulf-Heimsoth M, Jonkers IC, Lammers JW, Wouters IM, Doekes G, Wisnewski AV, Heederik D: Respiratory symptoms, sensitization, and exposure response relationships in spray painters exposed to isocyanates. Am J Respir Crit Care Med 2007, 176(11):1090-1097.

3. Mapp CE: "Occupational asthma": a matter of concern. Eur Respir J 1994, 7(1):1.

4. Baur $X$, Wieners D, Marczynski B: Late asthmatic reaction caused by naphthylene-1,5 diisocyanate. Scand I Work Environ Health 2000, 26(1):78-80.

5. Malo JL, Lemiere C, Desjardins A, Cartier A: Prevalence and intensity of rhinoconjunctivitis in subjects with occupational asthma. Eur Respir J 1997, 10(7):1513-1515.

6. Merget R, Marczynski B, Chen Z, Remberger K, Raulf-Heimsoth M, Willrot PO, Baur X: Haemorrhagic hypersensitivity pneumonitis due to naphthylene1,5-diisocyanate. Eur Respir J 2002, 19(2):377-380.

7. Dykewicz MS: Occupational asthma: current concepts in pathogenesis, diagnosis, and management. J Allergy Clin Immunol 2009, 123(3):519-528, quiz 529-530.

8. Redlich CA, Herrick CA: Lung/skin connections in occupational lung disease. Curr Opin Allergy Clin Immunol 2008, 8(2):115-119.

9. Boulet LP, Lemiere C, Gautrin D, Cartier A: New insights into occupational asthma. Curr Opin Allergy Clin Immunol 2007, 7(1):96-101.

10. Baur $X$ : Evidence for allergic reactions in isocyanate asthma. J Allergy Clin Immunol 2007, 119(3):757-758, author reply 758.

11. Monso E, Cloutier Y, Lesage J, Perreault G, Malo JL: What is the respiratory retention of inhaled hexamethylene di-isocyanate? Eur Respir J 2000, 16(4):729-730.

12. Karlsson D, Dahlin J, Skarping G, Dalene M: Determination of isocyanates, aminoisocyanates and amines in air formed during the thermal degradation of polyurethane. J Environ Monit 2002, 4(2):216-222.

13. Rosenberg C, Nikkila K, Henriks-Eckerman ML, Peltonen K, Engstrorm K: Biological monitoring of aromatic diisocyanates in workers exposed to thermal degradation products of polyurethanes. J Environ Monit 2002, 4(5):711-716

14. Sepai O, Henschler D, Sabbioni G: Albumin adducts, hemoglobin adducts and urinary metabolites in workers exposed to 4,4'-methylenediphenyl diisocyanate. Carcinogenesis 1995, 16(10):2583-2587.

15. Sabbioni G, Wesp H, Lewalter J, Rumler R: Determination of isocyanate biomarkers in construction site workers. Biomarkers 2007, 12(5):468-483.

16. Creely KS, Hughson GW, Cocker J, Jones K: Assessing isocyanate exposures in polyurethane industry sectors using biological and air monitoring methods. Ann Occup Hyg 2006, 50(6):609-621.

17. Pronk A, Yu F, Vlaanderen J, Tielemans E, Preller L, Bobeldijk I, Deddens JA, Latza U, Baur X, Heederik D: Dermal, inhalation, and internal exposure to 1,6-HDI and its oligomers in car body repair shop workers and industrial spray painters. Occup Environ Med 2006, 63(9):624-631.
18. Lemiere C, Bai T, Balter M, Bayliff C, Becker A, Boulet LP, Bowie D, Cartier A, Cave A, Chapman K, et al: Adult Asthma Consensus Guidelines update 2003. Can Respir J 2004, 11(Suppl A):9A-18A.

19. Baur X, Marek W, Ammon J, Czuppon AB, Marczynski B, Raulf-Heimsoth M, Roemmelt $\mathrm{H}$, Fruhmann $\mathrm{G}$ : Respiratory and other hazards of isocyanates. Int Arch Occup Environ Health 1994, 66(3):141-152.

20. Schutze D, Sepai O, Lewalter J, Miksche L, Henschler D, Sabbioni G: Biomonitoring of workers exposed to 4,4'-methylenedianiline or $4,4^{\prime}$ methylenediphenyl diisocyanate. Carcinogenesis 1995, 16(3):573-582.

21. Bolognesi C, Baur X, Marczynski B, Norppa H, Sepai O, Sabbioni G: Carcinogenic risk of toluene diisocyanate and 4,4'-methylenediphenyl diisocyanate: epidemiological and experimental evidence. Crit Rev Toxicol 2001, 31(6):737-772.

22. Tinnerberg $\mathrm{H}$, Mattsson C: Usage of air monitoring and biomarkers of isocyanate exposure to assess the effect of a control intervention. Ann Occup Hyg 2008, 52(3):187-194.

23. Skarping G, Brorson T, Sango C: Biological monitoring of isocyanates and related amines. III. Test chamber exposure of humans to toluene diisocyanate. Int Arch Occup Environ Health 1991, 63(2):83-88.

24. Brorson T, Skarping G, Sango C: Biological monitoring of isocyanates and related amines. IV. 2,4- and 2,6-toluenediamine in hydrolysed plasma and urine after test-chamber exposure of humans to 2,4- and 2,6toluene diisocyanate. Int Arch Occup Environ Health 1991, 63(4):253-259.

25. Rosenberg C, Savolainen H: Determination in urine of diisocyanatederived amines from occupational exposure by gas chromatographymass fragmentography. Analyst 1986, 111(9):1069-1071.

26. Kaaria $\mathrm{K}$, Hirvonen $\mathrm{A}$, Norppa $\mathrm{H}$, Piirila $\mathrm{P}$, Vainio H, Rosenberg C: Exposure to $4,4^{\prime}$-methylenediphenyl diisocyanate (MDI) during moulding of rigid polyurethane foam: determination of airborne MDI and urinary 4,4'methylenedianiline (MDA). Analyst 2001, 126(4):476-479.

27. Brorson T, Skarping G, Sandstrom JF, Stenberg M: Biological monitoring of isocyanates and related amines. I. Determination of 1,6-hexamethylene diamine (HDA) in hydrolysed human urine after oral administration of HDA. Int Arch Occup Environ Health 1990, 62(1):79-84.

28. Sakai T, Morita Y, Roh J, Kim H, Kim Y: Improvement in the GC-MS method for determining urinary toluene-diamine and its application to the biological monitoring of workers exposed to toluene-diisocyanate. Int Arch Occup Environ Health 2005, 78(6):459-466.

29. Kennedy AL, Stock MF, Alarie Y, Brown WE: Uptake and distribution of $14 \mathrm{C}$ during and following inhalation exposure to radioactive toluene diisocyanate. Toxicol Appl Pharmacol 1989, 100(2):280-292.

30. Littorin M, Truedsson L, Welinder H, Skarping G, Martensson U, Sjoholm AG: Acute respiratory disorder, rhinoconjunctivitis and fever associated with the pyrolysis of polyurethane derived from diphenylmethane diisocyanate. Scand J Work Environ Health 1994, 20(3):216-222.

31. Lind P, Dalene M, Skarping G, Hagmar L: Toxicokinetics of 2,4- and 2,6toluenediamine in hydrolysed urine and plasma after occupational exposure to 2,4- and 2,6- toluene diisocyanate. Occup Environ Med 1996, 53(2):94-99.

32. Dalene $M$, Skarping $G$, Lind P: Workers exposed to thermal degradation products of TDI- and MDI-based polyurethane: biomonitoring of 2,4TDA, 2,6-TDA, and 4,4'-MDA in hydrolyzed urine and plasma. Am Ind Hyg Assoc J 1997, 58(8):587-591.

33. Dalene M, Jakobsson K, Rannug A, Skarping G, Hagmar L: MDA in plasma as a biomarker of exposure to pyrolysed MDI-based polyurethane: correlations with estimated cumulative dose and genotype for $\mathrm{N}$ acetylation. Int Arch Occup Environ Health 1996, 68(3):165-169.

34. Tinnerberg H, Skarping G, Dalene M, Hagmar L: Test chamber exposure of humans to 1,6-hexamethylene diisocyanate and isophorone diisocyanate. Int Arch Occup Environ Health 1995, 67(6):367-374.

35. Slatter $\mathrm{JG}$, Rashed MS, Pearson PG, Han DH, Baillie TA: Biotransformation of methyl isocyanate in the rat. Evidence for glutathione conjugation as a major pathway of metabolism and implications for isocyanate-mediated toxicities. Chem Res Toxicol 1991, 4(2):157-161.

36. Baur X, Budnik LT: [New data on occupational exposure to isocyanates]. Pneumologie 2009, 63(11):656-661.

doi:10.1186/1745-6673-6-9

Cite this article as: Budnik et al.: Elimination kinetics of diisocyanates after specific inhalative challenges in humans: mass spectrometry analysis, as a basis for biomonitoring strategies. Journal of Occupational Medicine and Toxicology 2011 6:9. 